Emmanuel C.M. Mlyashimbi*, Joachim Mariën, Didas N. Kimaro, Akwilin J.P. Tarimo, Robert S. Machang'u, Rhodes H. Makundi, Moses Isabirye, Apia W. Massawe, Herwig Leirs, Mashaka E. Mdangi, Steven R. Belmain and Loth S. Mulungu

\title{
Home ranges, sex ratio and recruitment of the multimammate rat (Mastomys natalensis) in semi-arid areas in Tanzania
}

https://doi.org/10.1515/mammalia-2019-0048

Received April 18, 2019; accepted November 5, 2019

Abstract: Investigation of home ranges, sex ratio and recruitment of the multimammate rat (Mastomys natalensis) in semi-arid areas of Tanzania was conducted in maize and fallow fields using the capture-mark-release (CMR) technique. The aim of this study was to generate useful data for the management of $M$. natalensis. The relative home range size of $M$. natalensis was significantly higher during the wet $\left[544 \mathrm{~m}^{2} \pm 25\right.$ standard error (SE)] than during the dry $\left(447 \mathrm{~m}^{2} \pm 18 \mathrm{SE}\right)$ season, in males $\left(521 \mathrm{~m}^{2} \pm 23 \mathrm{SE}\right)$ than in females $\left(450 \mathrm{~m}^{2} \pm 17 \mathrm{SE}\right)$ and in adults $\left(576 \mathrm{~m}^{2} \pm 34\right.$ $\mathrm{SE}$ ) than in juveniles $\left(459 \mathrm{~m}^{2} \pm 16 \mathrm{SE}\right)$. However, there were no significant differences between habitats. Sex ratio was not significantly different $(\mathrm{p}=0.44)$ between habitats. Recruitment was significantly higher $(\mathrm{p}=0.000)$ in maize fields $($ mean $=0.43)$ than in fallow land $($ mean $=0.32)$ and differed significantly over time $(\mathrm{p}<0.0001)$ with the

*Corresponding author: Emmanuel C.M. Mlyashimbi, Department of Crop Science and Horticulture, Sokoine University of Agriculture, P.O. Box 3005, Morogoro, Tanzania; and Pest Management Centre, Sokoine University of Agriculture, P.O. Box 3110, Morogoro,

Tanzania, e-mail: ecmm14@yahoo.com

Joachim Mariën and Herwig Leirs: Evolutionary Ecology Group, Universiteit Antwerpen, Universiteitsplein 1, 2610 Antwerp,

Belgium

Didas N. Kimaro: Department of Engineering Sciences and Technology, Sokoine University of Agriculture, P.O. Box 3003, Morogoro, Tanzania

Akwilin J.P. Tarimo: Department of Crop Science and Horticulture, Sokoine University of Agriculture, P.O. Box 3005, Morogoro, Tanzania

Robert S. Machang'u, Rhodes H. Makundi, Apia W. Massawe and Loth S. Mulungu: Pest Management Centre, Sokoine University of Agriculture, P.O. Box 3110, Morogoro, Tanzania

Moses Isabirye: Faculty of Natural Resources and Environment, Busitema University, P.O. Box 236, Tororo, Uganda

Mashaka E. Mdangi: Training, Extension Services and Research, Ministry of Agriculture, P.O. Box 2182, Dodoma, Tanzania

Steven R. Belmain: Natural Resources Institute, University of

Greenwich, Chatham Maritime, Kent, UK highest recruitment recorded from April to July and the lowest from October to December. Management strategies should focus on managing rodents inhabiting maize fields using methods that affect their recruitment in order to reduce the population increase of $M$. natalensis.

Keywords: habitats; home range; recruitment; rodent pests; semi-arid.

\section{Introduction}

Rodent pests may have a severe impact on crop production in many agro-ecosystems around the world (Mulungu et al. 2003, Monadjem et al. 2011, John 2014). They are also carriers of a variety of potentially deadly diseases such as bubonic plague, hantaviruses, Lassa fever and typhus (Taylor et al. 2008, Kernéis et al. 2009, Meerburg et al. 2009, Neerinckx et al. 2010, Katakweba et al. 2012). It has been reported that many rodent pest species show large spatial and temporal fluctuations in their population dynamics (Mulungu et al. 2013) and, as a result, most of them exhibit striking population irruptions during and immediately after years of high rainfall (Leirs et al. 1996, Jaksic 2001, Meserve et al. 2003) because of increased food resources (Lima et al. 2006, Mulungu et al. 2011). Mastomys natalensis (Smith, 1834) is the most abundant and dominant rodent pest species in sub-Saharan Africa, and its outbreaks and impact to agriculture have been reported by several studies (Leirs et al. 1996, Mulungu et al. 2003, 2013).

Despite some knowledge of the seasonal changes in population and breeding patterns (Mlyashimbi et al. 2019) and diet (Mlyashimbi et al. 2018) of Mastomys natalensis in maize agro-ecosystems in semi-arid areas of Tanzania, their home ranges, sex ratio and recruitment within this system are unknown. Home range is typically used to assess the impact of habitat fragmentation on populations of small mammals (Gehring and Swihart 2004). In addition, it has been used to test behavioral hypotheses regarding cycles of population fluctuations in several 
small mammal species such as microtine rodents (Cutrera et al. 2006). The home ranges of animals can shift in size and position over time due to fluctuations in resources and risk (Byrne and Chamberlain 2011). In deer mice [Peromyscus maniculatus (Wagner, 1845)], for example, the home range was smaller in areas when food was available, whereas in areas of poor food quality, it was larger. In addition, many small mammals expand their home ranges in the summer when food is in scarcity, also coinciding with mating and recruitment (Cooney et al. 2015).

Mastomys spp. and Arvicanthis spp. have been reported to have more overlap in home ranges between opposite sexes (Taitt 1981) (Workneh et al. 2006). The home ranges of reproductive females of Mastomys natalensis were greater than those of non-reproductive ones (Workneh et al. 2006). In West Java, for example, ricefield rats [Rattus argentiventer (Robinson and Kloss, 1916)] react to harvest-induced changes in habitat structure by relocating their home ranges on average $300-400 \mathrm{~m}$ to piles of rice straw on the fields and to unharvested areas. This results in a postharvest decrease in home range size, which may indicate an immediate response to increased predation risk (Jacob et al. 2003).

It is believed that sex ratio reflects the ability of the species to respond to natural selection (Wu et al. 2006). A sex ratio of 1:1 is favored in polygamous species such as Rattus rattus (Linnaeus, 1758) when food is abundant while for Mus musculus the sex ratio differs from 1:1, with a higher recorded capture of males (Wright et al. 1988). Gomez et al. (2008) reported variation in the sex ratio in the same species across different habitats and seasons in different years in Argentina. This variation may be an effect of the high density of individuals, which generates a system of hierarchies and where subordinate males increase their area of activity during reproduction (Hernández-Betancourt et al. 2003). Males cover areas in search of food sources or females with which to mate, but are generally repelled by dominant males, which leads to an increased probability of capture. This contrasts with reproductive females whose area of activity is smaller (Hernández-Betancourt et al. 2003, Frynta et al. 2005), especially during events such as pregnancy and lactation (Mikesic and Drickamer 1992). Mastomys natalensis populations in single cropping areas can have a marked reproductive seasonality (Leirs 1994); however, in semi-arid areas of Tanzania, M. natalensis populations can exhibit almost continuous breeding patterns (Mlyashimbi et al. 2018) due to optimal conditions for reproduction throughout the year.

Another important parameter that determines population outbreaks of rodents is recruitment, which can be defined as the temporal measure of the proportion of new individuals brought into the population (Massawe et al. 2005, Mulungu et al. 2015a). Recruitment can differ between agro-ecosystems; for example, Mastomys natalensis had higher recruitment rates in slash-and-burn compared to tractor-ploughed maize fields (Massawe et al. 2005). Variations in reproductive activity, particularly the onset and termination of the reproductive period, can affect recruitment (Makundi et al. 2005) as well as interactions between humans and rodents (Massawe et al. 2012). The densities of Mastomys are usually higher at disturbed areas, e.g. agricultural fields than in natural environments (Monadjem and Perrin 2003, Massawe et al. 2007, Mohr et al. 2007) where the animals expand their home range (Cooney et al. 2015) and alter their sex ratio (Gomez et al. 2008).

Information on the home range, sex ratio and recruitment of Mastomys natalensis in semi-arid areas of Tanzania is limited; however, such knowledge is critical for the control of rodent pest species as these factors determine whether or not the level of control is sufficient to keep the population of the pest low. The main (null) hypothesis in this study was that the home range size of $M$. natalensis would not be affected by habitat type, season, sex, and age or population density. We furthermore hypothesized that habitat type does not affect the sex ratio or recruitment rate of $M$. natalensis. Results of this study can be used to better inform management strategies.

\section{Materials and methods}

\section{Location of the study}

This study was conducted in Isimani division in Iringa region, Tanzania. The study area is located between $7^{\circ} 25^{\prime}$ $0.4^{\prime \prime} \mathrm{m} \mathrm{S}$ and $35^{\circ} 48^{\prime} 12.6^{\prime \prime} \mathrm{m} \mathrm{E}$ at an elevation of between 1073 and $1356 \mathrm{~m}$ above sea level (Figure 1). It has a unimodal rainfall pattern with distinct dry and wet seasons. The mean annual precipitation ranges from 200 to $750 \mathrm{~mm} /$ year. It is characterized by low erratic rainfall and periodic droughts giving it a characteristic semi-arid nature where precipitation is below potential evapotranspiration.

The dry period at Isimani division is from May to November, whereas the wet season is between December and April. Land use consists of maize fields interspersed with fallow land with soils varying from black clay and sandy loamy soils. Maize is the primary crop which reaches physiological maturity in May and is harvested in July. 


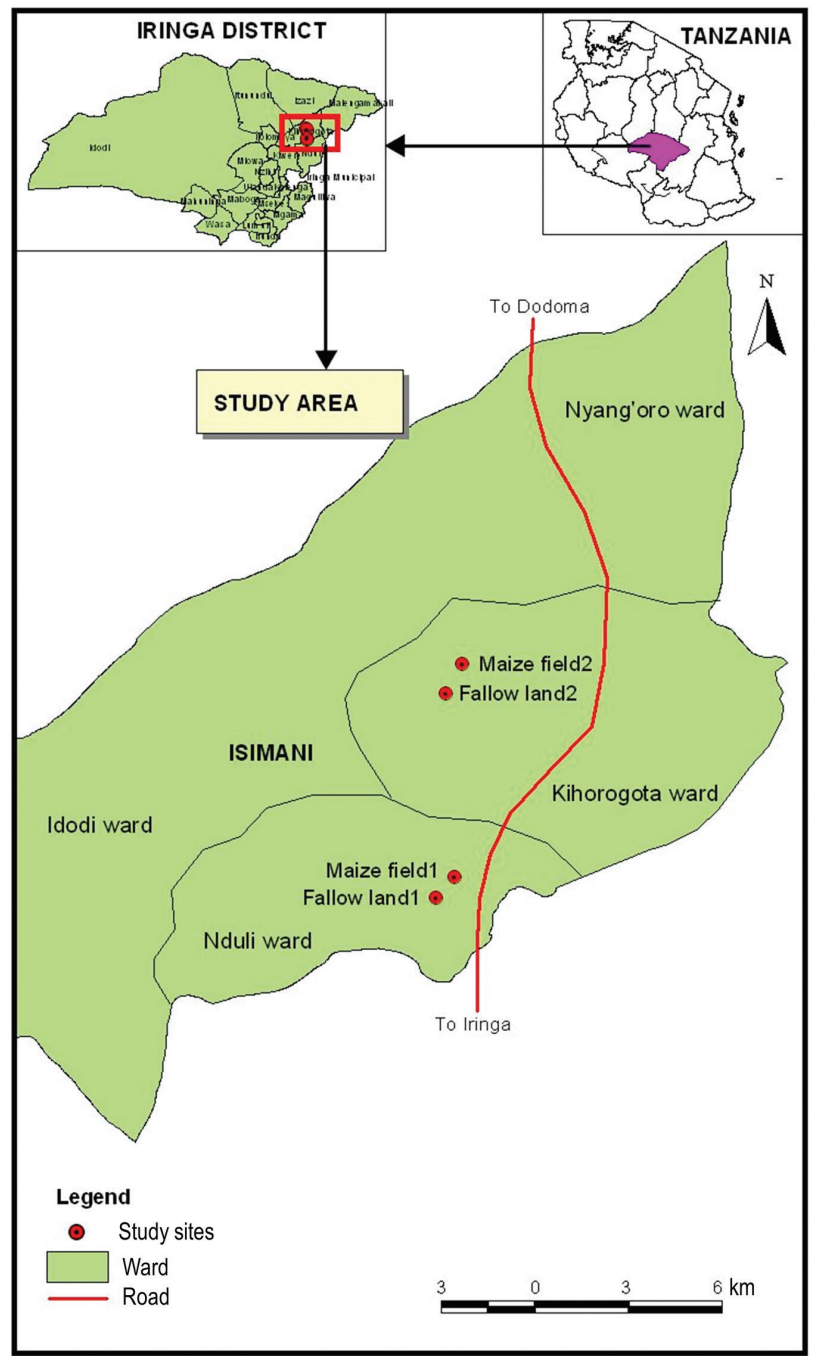

Figure 1: Location of the study sites - Ismani division, Iringa region, Tanzania.

\section{Trapping rodent species}

A capture-mark-recapture study was carried out from February 2015 to January 2018. Four $60 \mathrm{~m} \times 60 \mathrm{~m}$ trapping grids of which the first two in maize fields (one in clay soils and the other in sandy loamy soils) and the other two in fallow land in similar soils as maize fields were laid and set in famers' fields and separated by at least $300 \mathrm{~m}$. This distance between grids is more than 20 times the average home range radius of Mastomys natalensis (Leirs et al. 1996, Borremans et al. 2014). Mastomys natalensis is the major rodent pest species in the study area (Mlyashimbi et al. 2018). Each grid consisted of seven parallel lines, $10 \mathrm{~m}$ apart, and seven trapping stations per line (making a total of 49 trapping stations/grid). One Sherman LFA live trap $(8 \times 9 \times 23 \mathrm{~cm}$, H.B. ShermanTraps Inc., Tallahassee, FL, USA) was set at each trapping station for three consecutive nights at intervals of 4 weeks (i.e. a robust design with primary trapping session every month and secondary trapping session during 3 days within that month). Traps were baited in the late afternoon with peanut butter mixed with maize bran/flour and inspected early in the following morning as described by Mulungu et al. (2011).

\section{Data collection}

Captured animals were identified to the species level following the established taxonomic nomenclature (Hickman et al. 2006). Data collected included rodent species, weight, field and coordinates of the trapping station, animal marking code, sex age (adult and juvenile) and reproductive status, i.e. perforated or closed vagina for female, and scrotal or non-scrotal testes for male (Leirs 1994).

\section{Data analysis}

\section{Home range size}

Home ranges were calculated based on capture-markrelease (CMR) data for all animals that were captured at more than one primary trapping session (for an overview on the number of primary and secondary captures, refer to Supplementary Figure 1). These animals were considered to be resident (in contrast to animals that were only captured during one secondary trapping session) and were therefore of primary interest for our statistical analysis. Home range size was calculated using the minimum convex polygon method (MCP) with an inclusive boundary strip of $5 \mathrm{~m}$ (Borremans et al. 2014). Although previous studies have shown that MCP underestimates the true home range size of Mastomys natalensis (especially if they are captured only a few times), this was not of concern in our study as we were only interested in the relative differences (Leirs et al. 1997). By using a linear model, we investigated if there were significant differences in the relative home range size between habitats (clay-fallow, clay-maize, loamy-fallow, loamy-maize); seasons (dry, wet); sex (male, female) and reproductive status (adult, juvenile). Home range size data were log transformed in order to meet the assumption of normality. The R packages "adehabitatHR", "dplyr" and "ggplot2" were used 
for this analysis (Calenge 2006, Wickham 2009, Wickham et al. 2018).

\section{Sex ratio}

Variation in sex ratio was determined in both habitats and for different months. In this study, sex ratio is defined as the proportion of females in the whole population and was done in favor of females. Male rodents were ignored as they can be active throughout the season and one male can encounter many females in one season. The data were subjected to SAS software (SAS Institute Inc., Cary, NC, USA, 1997) where habitats and months were factors. The means separation was done using the Tukey post-hoc test to determine the significant difference of means between habitats and months.

\section{Recruitment}

The number of new animals (unmarked) out of the total captures for each trapping session was used to establish the proportion of new recruits into the population. The proportions of new individuals of Mastomys natalensis were compared between months and habitats, and data were subjected to a two-way analysis of variance (ANOVA) using SAS software (1997). The means separation was done using the Tukey post-hoc test to determine the significant difference of means between habitats and months.

\section{Results}

\section{Home ranges of Mastomys natalensis}

The relative home range size of Mastomys natalensis was significantly higher during the wet than during the dry season $\left[544 \mathrm{~m}^{2} \pm 25\right.$ standard error (SE) and $447 \mathrm{~m}^{2} \pm 18$ SE, $\mathrm{n}_{\text {wet }}=287$ and $\mathrm{n}_{\text {dry }}=394$, respectively; $\chi^{2}=1.9$, $\mathrm{df}=1, \mathrm{p}=0.0150$ ] (Figure 2), in males than in females $\left(521 \mathrm{~m}^{2} \pm 23 \mathrm{SE}\right.$ and $450 \mathrm{~m}^{2} \pm 17 \mathrm{SE}, \mathrm{n}_{\text {males }}=360$ and $\mathrm{n}_{\text {females }}=321$, respectively; $\left.\chi^{2}=4.5, \mathrm{df}=1, \mathrm{p}=0.0367\right)$ and in adults than in juveniles $\left(576 \mathrm{~m}^{2} \pm 34 \mathrm{SE}\right.$ and $459 \mathrm{~m}^{2} \pm 16$ SE; $\mathrm{n}_{\text {adults }}=168$ and $\mathrm{n}_{\text {juveniles }}=513$, respectively; $\chi^{2}=8.5$, $\mathrm{df}=1, \mathrm{p}=0.0032$ ). Differences between the categories and their interactions are presented in the Supplementary Figures $2-4$. No significant differences were found between habitats $\left(\chi^{2}=5.1, \mathrm{df}=3, \mathrm{p}=0.1808\right.$ (Figure 2$)$.

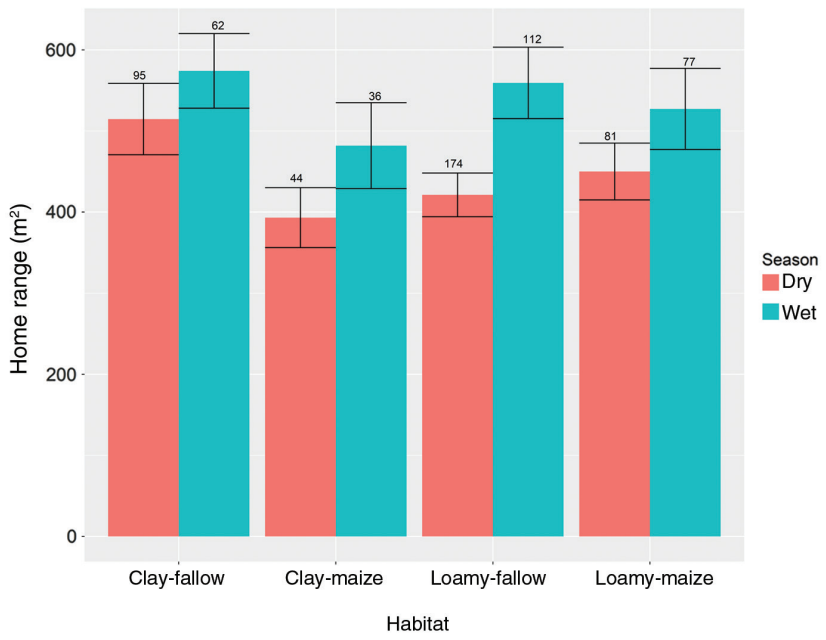

Figure 2: Mean $( \pm \mathrm{SE})$ relative home range size of Mastomys natalensis as per habitat and season calculated by the minimum convex polygon method.

Bars indicate standard errors on the means. Numbers on top of the error bars represent the sample size of each group.

\section{Sex ratio}

Statistically, there was no difference $\left(\mathrm{F}_{1,119}=0.59, \mathrm{p}=0.44\right)$ between habitats, whereby a relatively higher proportion of female Mastomys natalensis were observed in the maize field (mean, 0.42, $\mathrm{n}=311$ ) than in fallow land (mean, 0.39, $\mathrm{n}=413)$ (Figure 3). No differences $\left(\mathrm{F}_{11,119}=1.72, \mathrm{p}=0.08\right)$ in sex ratio of $M$. natalensis were found on the interactions between months and habitats. However, there was a significant effect $\left(\mathrm{F}_{11,119}=2.01, \mathrm{p}=0.0334\right)$ across months, whereby the highest number of $M$. natalensis was recorded in April (mean $=0.59 \pm 0.06, \mathrm{n}=48$ ) and the lowest in September and October (mean $=0.28 \pm 0.06$, $\mathrm{n}=66$ ), respectively.

\section{Recruitment}

Recruitment was significantly different $\left(F_{1,119}=14.34\right.$, $\mathrm{p}=0.0002$ ) between habitats, whereby a higher proportion of Mastomys natalensis was recorded in maize fields (mean $=0.43, \mathrm{n}=764$ ) than in fallow land (mean $=0.32$, $\mathrm{n}=1018)$ (Figure 4). A significant effect $\left(\mathrm{F}_{11,119}=10.17\right.$, $\mathrm{p}<0.0001)$ was also observed across the months, with the highest recruitment of $M$. natalensis recorded from April to July, and the lowest from September to December. However, there was no significant difference $\left(F_{11,119}=1.72, p=0.077\right)$ in the interaction between months and fields. 


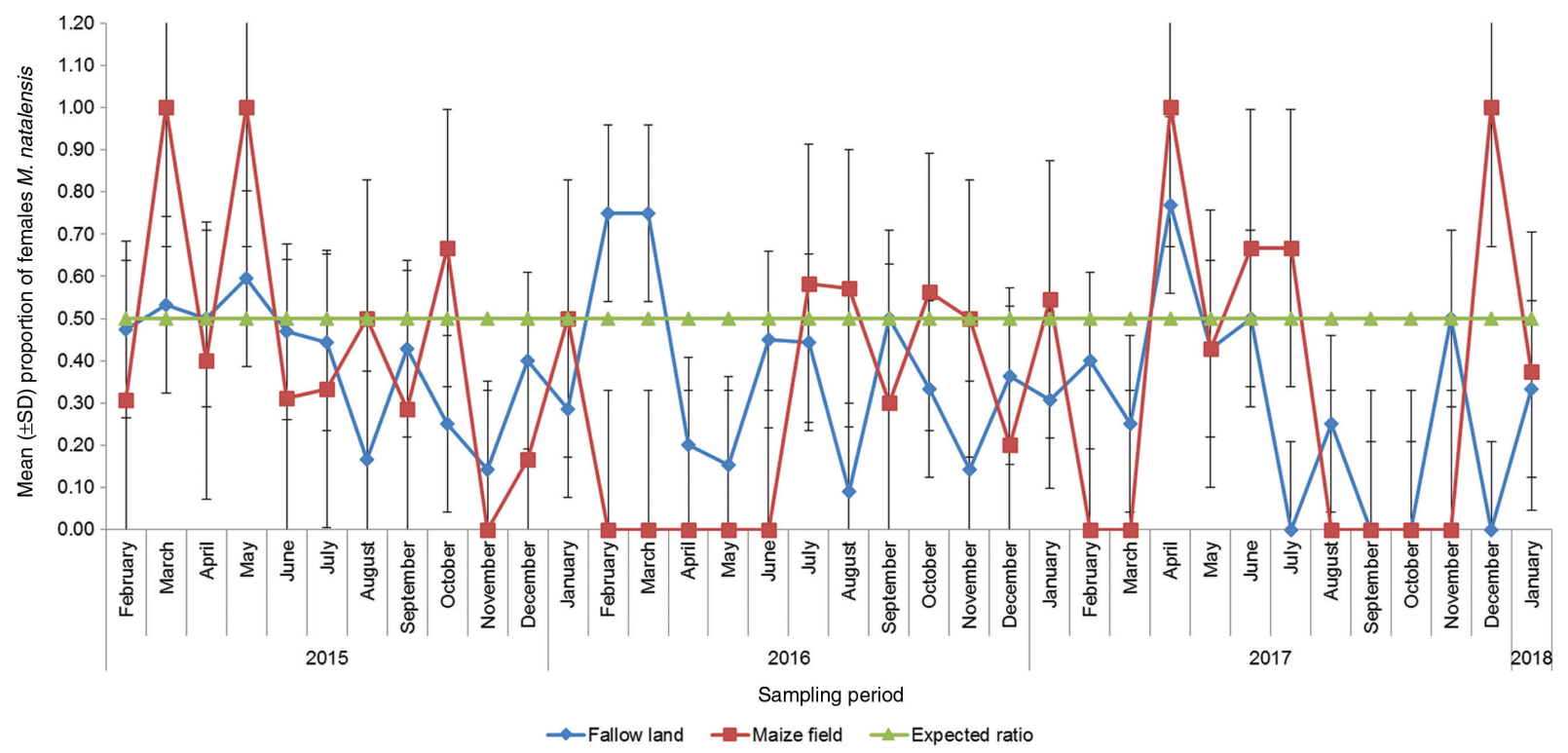

Figure 3: Mean $( \pm \mathrm{SE})$ sex ratio of Mastomys natalensis captured in the study site of Isimani division, Iringa, Tanzania

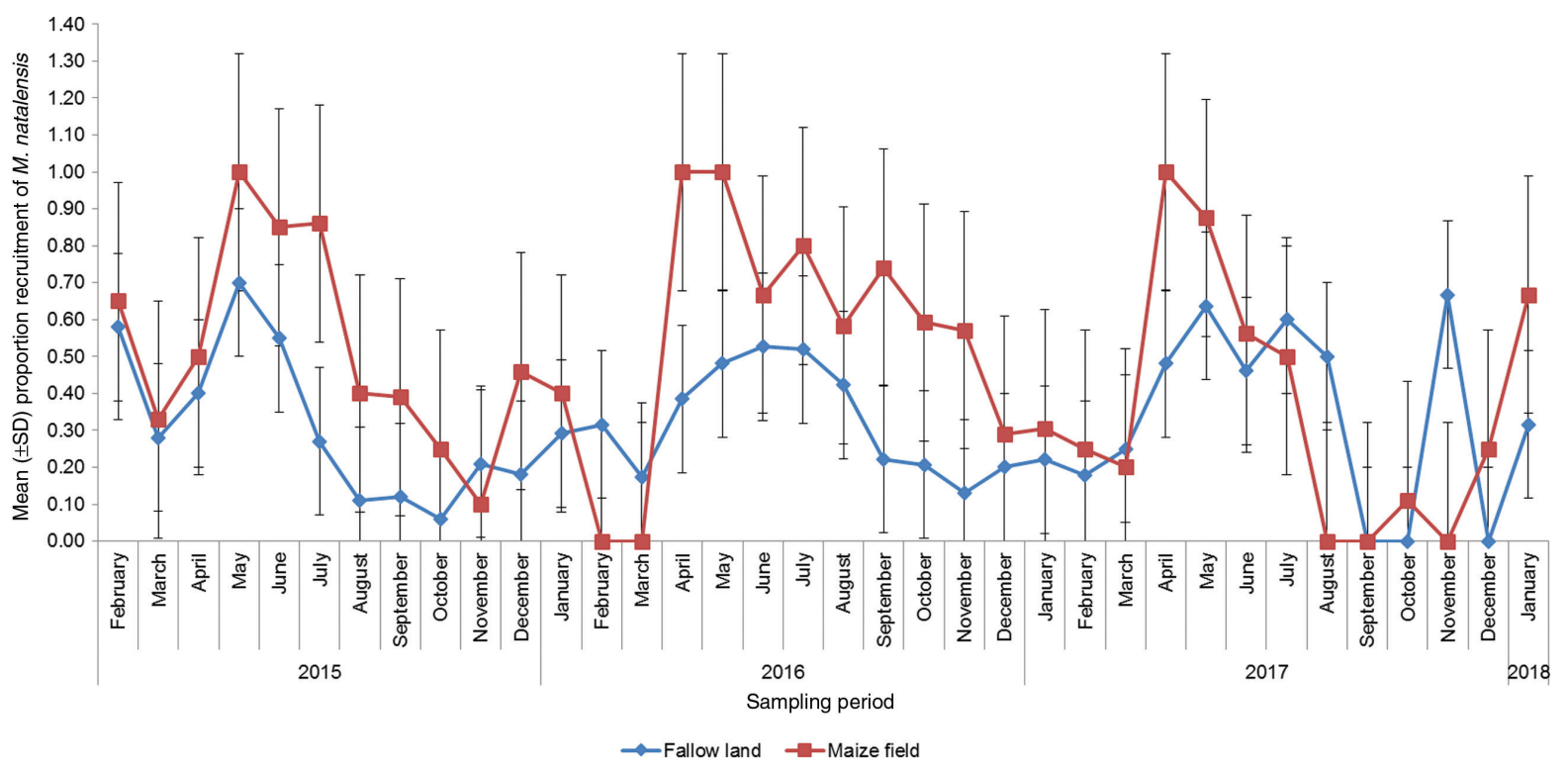

Figure 4: Mean ( \pm SE) recruitment of $M$. natalensis observed in the study site of Isimani division, Iringa, Tanzania.

\section{Discussion}

The home range of animals is a spatial measure that represents the area in which individuals regularly move in search of resources and mates (Cooney et al. 2015) and caring for young (Cutrera et al. 2006). The current study found no difference in the home range size of Mastomys natalensis between habitat types (maize fields and fallow lands). These results are consistent with those found in previous studies on $M$. natalensis in rice fields, maize and fallow lands (Leirs et al. 1996, Monadjem and Perrin 1998, Borremans et al. 2014, Mulungu et al. 2015b). This suggests that $M$. natalensis can easily reside in different habitat types.

In the current study, larger home ranges of Mastomys natalensis were observed during the wet season (plenty of food) than during the dry season (food scarcity). In contrast, it has been reported that the home ranges of animals can be smaller in areas where food was available, while it was larger in areas of low food availability (Workneh 
et al. 2006). Besides food availability, it is known that many small mammals expand their home ranges during the reproductive period (Cooney et al. 2015). In this study, most $M$. natalensis were at the peak of their breeding during the wet season in April to July (Mlyashimbi et al. 2019), which would support a home range expansion in response to recruitment. In general, home range size of M. natalensis in the current study was influenced by sex and breeding period, and partly by population density. During the wet season, the sex ratio of $M$. natalensis became skewed toward females in April (with long rains) and skewed toward males during the dry period in September and October in both habitats. This could be due to reproductive activity of females during the wet season when they tend to search food and males for mating (Mlyashimbi et al. 2019). This could also be observed by the higher number of recruitment during the dry season, leading to intense intra-specific competition and larger home ranges for males (Mulungu et al. 2013).

The current study also found larger home range sizes for male than female Mastomys natalensis. This could be attributed to the sexual competition among them to succeed in mating. Similar findings by Workneh et al. (2006) reported that reproductively active males maintain larger home ranges than females because they have to eat more food to acquire more energy for mating success. In small mammals, males typically have home ranges that can be twice as large as those of females, and their ranges overlap extensively with females and other males (Stickel 1954). Males compete for mates whilst females seek opportunities for their young to reach reproductive maturity (West and Godfray 1997). While males maximize their reproductive success by mating with as many females as possible (Wolff et al. 2002), females typically provide greater parental investment than males, which results in differential use of space and alters the distribution of male reproductive success after a period of exceptional recruitment. Several studies have observed that new recruits reproduced, and exhibit different spacing patterns, due to age-specific life history trade-offs or interactions with conspecifics (Hannon and Martin 2006, Hoset et al. 2008, Welsh et al. 2013, Shaner et al. 2017). According to Wolff et al. (2002), females have a greater negative effect on juvenile recruitment and reproductive development than do males. Moreover, sex ratio is the result of female reproductive strategy, specifically whether she mates once upon becoming reproductively active or continuously throughout her reproductive life.

The current study showed larger home ranges for adult Mastomys natalensis when compared to juveniles. This could be due to the fact that the juveniles are limited in their exploratory behavior due to aggressiveness of older individuals, hence affecting the sex ratio and recruitment of $M$. natalensis. In similar findings by Eiris and Barreto (2009), younger individuals are limited to explore new territories due to aggression by older or more dominant animals. The relative fitness of juveniles could be affected by several factors such as environmental conditions, maternal age or reproductive strategy resulting in obscure sex ratio bias patterns. According to Martin and FestaBianchet (2011), offspring sex ratio manipulation was an adaptive response to differences in fitness between sons and daughters. Changes in that sex-specific fitness with maternal state should lead to variation in sex ratio bias.

The variations in home ranges, sex ratio and recruitment observed in the current study site are likely to be mediated by intra-specific competition for food in maize fields and/or refuge in fallow land. According to Mulungu et al. (2011), availability of high-quality food is arguably the most important parameter affecting rodent recruitment in maize/fallow mosaic habitats. In the current study site, the highest recruitment was observed during the wet season in April to May. Mulungu et al. (2011, 2015b) observed higher recruitment in rice fields, related to the presence of highquality food that is preferred by Mastomys natalensis. Rodents can adjust to the cropping system, establishing during the initial period of the crop and breeding during crop growing period, and are capable of rapid population growth and emigration after crop harvest, depending upon food availability (Sarwar et al. 2011).

\section{Conclusion}

Based on this study, we demonstrated that home range, sex ratio and recruitment rates of Mastomys natalensis differed with seasons and months. Home ranges were observed to be higher during the wet than dry seasons, in males than in females and in adults than juveniles. Sex ratio and recruitment rates were observed to be higher in maize fields than in fallow lands. The highest recruitment was observed in April to May that sustained higher densities of rodent due to the presence of high quality of food that is preferred by M. natalensis. The implications of these findings in terms of management in semi-arid areas should aim at rodent pest species inhabiting maize fields using methods that disturb their recruitment in order to reduce population increase of $M$. natalensis. Unfortunately, most farmers apply rodent control actions after serious crop damage is observed, which our results would suggest is too late to have any meaningful impact on crop losses. Rodent pest management must be done before 
substantial recruitment takes place, and this will require concerted efforts to raise the awareness and knowledge of farmers on the importance of and tools for early monitoring and management of rodent pests.

Acknowledgments: We are grateful to the Ecologicallybased Management of Rodent Pests in Maize and Rice in East Africa project granted to Sokoine University of Agriculture (grant no. OPP1112579) supported by the Bill and Melinda Gates Foundation. We appreciate the excellent field assistance from Khalid S. Kibwana, Omary Kibwana and Ramadhani Kigunguli of the Pest Management Centre, Sokoine University of Agriculture, Morogoro, Tanzania.

\section{References}

Borremans, B., N.K. Hughes, J. Reijniers, V. Sluydts, A.A.S. Katakweba, L.S. Mulungu, C.A. Sabuni, R.H. Makundi and H. Leirs. 2014. Happily together forever: temporal variation in spatial patterns and complete lack of territoriality in a promiscuous rodent. Popul. Ecol. 56: 109-118.

Byrne, M.E. and M.J. Chamberlain. 2011. Seasonal space use and habitat selection of adult raccoons (Procyon lotor) in a Louisiana bottomland hardwood forest. Am. Midl. Nat. 166: 426-434.

Calenge, C. 2006. The package and habitat for the R software: a tool for the analysis of space and habitat use by animals. Ecol. Modell. 197: 516-519.

Cooney, S.A., E.M. Schauber and E.C. Hellgren. 2015. Ranging behavior of marsh rice rats in a southern Illinois wetland complex. J. Mammal. 96: 732-741.

Cutrera, A.P., C.D. Antinuchi, M.S. Mora and A.I. Vassallo. 2006. Home-Range and Activity Patterns of the South American Subterranean Rodent Ctenomys talarum. J. Mammal. 87: 1183-1191.

Eiris, G.C. and G.R. Barreto. 2009. Home range of marsh rats Holochilus ciureus, a rodent pest in rice fields of Venezuel. Intersciencia 34: 400-405.

Frynta, D., M. Slábová, H. Váchová, R. Volfová and P. Munclinger. 2005. Aggression and commensalism in house mouse: a comparative study across Europe and the Near East. Aggress. Behav. 31: 283-293.

Gehring, T.M. and R.K. Swihart. 2004. Home range and movement of long tailed weasels in a landscaped by agriculture. J. Mammal. 85: 79-86.

Gomez, M.D., J. Priotto, M.C. Provensal, A. Steinmann, E. Castillo and J.J. Polop. 2008. A population study of house mice (Mus musculus) inhabiting different habitats in an Argentine urban area. Int. Biodeterior. Biodegradation 62: 270-273.

Hannon, S. and K. Martin. 2006. Ecology of juvenile grouse during the transition to adulthood. J. Zool. 269: 422-433.

Hernández-Betancourt, S., W.R. López, P.J. Cimé and P.S. Medina. 2003. Area of activity, movement and social organization of Heteromys gaumeri Allen and Chapman, 1897 (Rodentia: Heteromydae) in a medium-sized sub-deciduous forest of Yucatan, Mexico. Zool Act. Mex. 90: 77-91.
Hickman, C., L. Roberts, S. Keen, A. Larson, H. l'Anson and D. Eisenhour. 2006. Integrated principles of zoology, $14^{\text {th }}$ ed. Boston MA: McGraw-Hill. pp. 910.

Hoset, K.S., J.F. Le, G.G. Gundersen and H. Steen. 2008. Home range size and overlap in female root voles: effects of season and density. Behav. Ecol. 19: 139-145.

Jacob, J., D. Nolte, R. Hartono, J. Subagja and Sudarmaji. 2003. Preand post-harvest movements of female rice-field rats in West Javanese rice fields. In: (G.R. Singleton, L.A. Hinds, C.J. Krebs and D.M. Spratt, eds.) Rats, mice and people: rodent biology and management. Australia Centre for International Agricultural Research, Canberra, ACT, Australia.

Jaksic, F.M. 2001. Ecological effects of El Niño in terrestrial ecosystems of western South America. Ecography 24: 241-250.

John, A. 2014. Rodent outbreaks and rice pre-harvest losses in Southeast Asia. Food Secur. 6: 249-260.

Katakweba, S.A., L.S. Mulungu, S. Eiseb, T.A. Mahlaba, R.H. Makundi, A.W. Massawe and S.R. Belmain. 2012. Prevalence of haemoparasite, leptospires and cocobacili with potential to human infection in the blood of rodents and shrews from selected localities in Tanzania, Namibia and Swaziland. Afr. Zool. 47: 119-127.

Kernéis, S., L. Koivogui, N. Magassouba, K. Koulemou, R. Lewis, A. Aplogan, R.F. Grais, P.J. Guerin and E. Fichet-Calvet. 2009. Prevalence and risk factors of Lassa seropositivity in inhabitants of the forest region of Guinea: a cross-sectional study. PLoS Negl. Trop. Dis. 3: 548.

Leirs, H. 1994. Population ecology of Mastomys natalensis (Smith, 1834: implications for rodent control in Africa. A report from Tanzania-Belgium Joint Rodent Research Project (1986-1989). Brussels: Agricultural Edition - Nr 35. Belgian Administration for Development Cooperation. pp. 268.

Leirs, H., W. Verheyen and R. Verhagen. 1996. Spatial patterns in Mastomys natalensis in Tanzania (Rodentia, Muridae). Mammalia 60: 545-555.

Leirs, H., R. Verhagen, C. Sabuni, P. Mwanjambe and W. Verheyen. 1997. Spatial patterns in Mastomys natalensis in Tanzania (Rodentia, Muridae). Belg. J. Zool. 127: 29-38.

Lima, M., M.A. Previtali and P.L. Meserve. 2006. Climate and small rodent dynamics in semi-arid Chile: the role of lateral and vertical perturbations and intra-specific processes. Clim. Res. 30: 125-132.

Makundi, R.H., A. Bekele, H. Leirs, A.W. Massawe, W. Rwamugira and L.S. Mulungu. 2005. Farmers' perceptions of rodents as crop pests: knowledge, attitudes and practices in rat management in Tanzania and Ethiopia. Belg. J. Zool. 135(Supplement) 153-157.

Martin, J.G. A. and M. Festa-Bianchet. 2011. Sex ratio bias and reproductive strategies: what sex to produce when? Ecology 92: 441-449.

Massawe, A.W., W. Rwamugira, H. Leirs, R.H. Makundi and L.S. Mulungu. 2005. Influence of land preparation methods and vegetation cover on population abundance of Mastomys natalensis in Morogoro, Tanzania. Belg. J. Zool. 135(Supplement): 187-190.

Massawe, A.W., W. Rwamugira, H. Leirs, R.H. Makundi and L.S. Mulungu. 2007. Do farming practices influence population dynamics of rodents? A case study of the multimammate field rats, Mastomys natalensis, in Tanzania. Afr. J. Ecol. 45: 293-301. 
Massawe, A.W., R.H. Makundi, L.S. Mulungu, A. Katakweba and T.N. Shayo. 2012. Breeding dynamics of rodent species inhabiting farm-fallow mosaic fields in Central Tanzania. Afr. Zool. 47: 128-137.

Meerburg, G.M., G.R. Singleton and A. Kijlstra. 2009. Rodent-borne diseases and their risks for public health. Crit. Rev. Microbiol. 35: 221-270.

Meserve, P.L., D.A. Kelt, W.B. Milstead and J.R. Gutiérrez. 2003. Thirteen years of shifting top-down and bottom-up control. BioScience 53: 633-646.

Mikesic, D.G. and L.C. Drickamer. 1992. Factors affecting homerange size in house mice (Mus musculus domesticus) living in outdoors enclosures. Am. Midl. Nat. 127: 31e40.

Mlyashimbi, E.C.M., J. Mariën, D.N. Kimaro, A.J.P. Tarimo, M. Isabirye, R.H. Makundi, A.W. Massawe, M.E. Mdangi, D. Kifumba, A. Nakiyemba, H. Leirs, S.R. Belmain and L.S. Mulungu. 2018. Relationships between seasonal changes in diet of multimammate rat (Mastomys natalensis) and its breeding patterns in semi-arid areas in Tanzania. Cogent Food Agric. 4: 1-13.

Mlyashimbi, E.C.M., B. Vanden Broecke, J. Mariën, D.N. Kimaro, A.J.P. Tarimo, R.S. Machang'u, M. Isabirye, R.H. Makundi, A.W. Massawe, P. Hieronimo, D. Kifumba, H. Leirs, M.E. Mdangi, S.R. Belmain and L.S. Mulungu. 2019. Influences of soil types on the population dynamics and survival of multimammate rat (Mastomys natalensis, Smith 1832) in semi-arid areas in Tanzania. Crop Prot. 24: 104829.

Mohr, K., H. Leirs, A. Katakweba and A. Machang'u. 2007. Monitoring rodents' movements with a biomarker around introduction and feeding foci in an urban environment in Tanzania. Afr. Zool. 42: 294-298.

Monadjem, A. and M. Perrin. 1998. The effect of supplementary food on the home range of the multi-mammate mouse Mastomys natalensis. S. Afr. J. Wildl. Res. 28: 1-3.

Monadjem, A. and M. Perrin. 2003. Population fluctuations and community structure of small mammals in a Swaziland grassland over a 3-year period. Afr. Zool. 38: 127-137.

Monadjem, A., T.A. Mahlaba, N. Dlamini, S.J. Eiseb, S.R. Belmain, L.S. Mulungu, A.W. Massawe, R.H. Makundi, K. Moh, J. Peter and P.J. Taylor. 2011. Impact of crop cycle on movement patterns of pest rodent species between fields and houses in Africa. Wildl. Res. 38: 603-609.

Mulungu, L.S., R.H. Makundi, H. Leirs, A.W. Massawe, S. VibePetersen and N.C. Stenseth. 2003. The rodent density - damage function in maize fields at early growth stage, pp 301-303. In: (G.R. Singleton, L.A. Hinds, C.J. Krebs and D.M. Spratt, eds.). Rats, mice and people: rodent biology and management. ACIAR Monograph No. 96, pp. 564.

Mulungu, L.S., T.A. Mahlaba, A.W. Massawe, J. Kennis, D. Crauwels, S. Eiseb, A. Monadjem, R.H. Makundi, A.S. Katakweba, H. Leirs and S.R. Belmain. 2011. Dietary differences of the multimammate mouse, Mastomys natalensis (Smith 1834). Across different habitats and seasons in Tanzania and Swaziland. Wildl. Res. 38: 640-646.

Mulungu, L.S., V. Ngowo, M. Mdangi, A.S. Katakweba, P. Tesha, F.P. Mrosso, M. Mchomvu, P.M. Sheyo and B.S. Kilonzo. 2013. Population dynamics and breeding patterns of Multimammate mouse, Mastomys natalensis (Smith 1834) in irrigated rice field in Eastern Tanzania. Pest Manag. Sci. 69: 371-377.
Mulungu, L.S., V. Ngowo, M.E. Mdangi, A.S. Katakweba, P. Tesha, F.P. Mrosso, M. Mchomvu, A.W. Massawe, A. Monadjem, B. Kilonzo and S.R. Belmain. 2015a. Survival and recruitment of the multimammate mouse, Mastomys natalensis (Smith 1834), in a rice agro-ecosystem. Mammalia 80: 205-210.

Mulungu, L.S., B.V. Borremans, V. Ngowo, M. Mdangi, A.S. Katakweba, P. Tesha, F.P. Mrosso, M. Mchomvu and B.S. Kilonzo. 2015b. Comparative study of movement patterns of Mastomys natalensis in irrigated rice and fallow fields in eastern Tanzania. Afr. J. Ecol. 53: 473-479.

Neerinckx, S., E. Bertheratc and H. Leirs. 2010. Human plague occurrences in Africa: an overview from 1877 to 2008. Trans. R. Soc. Trop. Med. Hyg. 104: 97-103.

Sarwar, M., M. Ashfaq and M.Y. Baig. 2011. The species complex, damage pattern and control of rodents (Mammalia: Rodentia) in Sugarcane (Saccharum officinarum L.) fields. Int. J. Plant Prod. 2: 145-150.

Shaner, P.J.L., A.Y. Yu, L. Ke and S.H. Li. 2017. Spacing behaviors and spatial recruitment of a wild rodent in response to parasitism. Ecosphere 8: e01780.

Stickel, L.F. 1954. A comparison of certain methods of measuring ranges of small mammals. J. Mammal. 35: 1-15.

Taitt, J.M. 1981. The effect of extra food on small rodent populations: 1. Deermice (Peromyscus maniculatus). J. Anim. Ecol. 50: 111-124.

Taylor, P.J., L. Arntzen, M. Hayter, M. Iles, J. Frean and S.R. Belmain. 2008. Understanding and managing sanitary risks due to rodent zoonoses in an African city: beyond the Boston Model. Integr. Zool. 3: 38-50.

Welsh, J., C. Goatley and D. Bellwood. 2013. The ontogeny of home ranges: evidence from coral reef fishes. Proc. Biol. Sci. 280: 2066.

West, S.A. and H.C.J. Godfray. 1997. Sex ratio strategies after perturbation of the stable age distribution. J. Theor. Biol. 186: 213-221.

Wickham, H. 2009. ggplot2: elegant graphics for data Analysis. Springer-Verlag, New York, USA. pp. 66.

Wickham, H., F. Romain, H. Lionel and M. Kirill. 2018. dplyr: a grammar of data manipulation. $R$ package version 0.7.5. Available from; https://CRAN.R-project.org/package=dplyr, visited on July 7, 2018.

Wolff, J.O., W.D. Edge and G. Wang. 2002. Effects of adult sex ratios on recruitment of juvenile gray-tailed voles, Microtus canicaudus. J. Mammal. 83: 947-956.

Workneh, G; A. Bekele, G. Belay and M. Balakrishnan. 2006. Home range and reproduction of rodents in Maynugus irrigation fields, Northern Ethiopia. Ethiop. J. Health Sci. 29: 57-62.

Wright, S.Y., C.B. Crawford and J.L. Anderson. 1988. Allocation of reproductive effect in Mus domesticus: response of offspring sex ratio and quality to social density and food availability. Behav. Ecol. Sociobiol. 23: 357-366.

Wu, S.Y., Y.K. Lin and H.T. Yu. 2006. Population ecology of the Southeast Asian house mouse (Muridae: Mus musculus castaneus) inhabiting rice granaries in Taiwan. Zool. Stud. 45: 467-474.

Supplementary Material: The online version of this article offers supplementary material (https://doi.org/10.1515/mammalia-20190048). 